\title{
Hypnotic control of interpolated activity in a short-term memory task'
}

\begin{abstract}
Hypnotic control may be used as a means of specifying the exact nature of the interpolated interval in shortterm memory, allowing for investigation of such items as time of rehearsal, amount of rehearsal and the like in a direct fashion. Conclusions for this demonstrative paper are limited to (a) a strong indication that level of nonspecific emotion is unrelated to memorial capacities and (b) while presence or absence of rehearsal is the dominant factor in determining performance in memory tasks, such variables as stimulus-rehearsal interval bear exploration.
\end{abstract}

\section{Problem}

The problem of the nature of interpolated activity in short-term memory has been a source of difficulty in the design and interpretation of memory experiments. Attempts to "control" time intervals, and rehearsals occurring within them, generally may be classed as efforts to fill such intervals with activity. The problem is to prevent rehearsal without specifically interfering with the to-be-learned materials (Peterson \& Peterson, 1959). The following two experimental exercises were efforts to use hypnosis, specifically posthypnotic suggestion in the waking state, as a control over the interpolated time period in a short-term memory situation.

\section{Experiment 1}

This experiment was conducted to test for possible results of a non-specific, non-cognitive, manipulation of emotional state when such manipulation was substituted for a standard interpolated activity in a short-term memory task. The hypnotic manipulation was as follows: $\mathrm{S}$ was instructed to associate different levels of subjective pleasure to four different cue cards (symbols drawn on $3 \times 5$ in unlined cards). $S$ was given practice in reaching the proper state on presentation of the cues before the experiment. The four different states, from neutral to maximum pleasure, were suggested. The states of pleasure corresponded to different levels of basal resistance (BRL). In contrast to these conditions, another condition representing the standard interpolated task of counting backwards by 3s from a given number was employed.

\section{Method}

$\mathrm{S}$ was an undergraduate at the University of Michigan who has been a trained hypnotic subject for more than a year. Time intervals for the experiment were 4 and 16 sec. S's instructions were to listen to the stimulus which was a consonant trigram selected from the 0-17 portion of the list of consonant trigrams in Underwood and Schulz (1960) and then immediately respond in the appropriate fashion to either a cue card or a 3-digit number. Cue cards were to elicit immediate emotional reaction until the word "recall"; numbers were to elicit the backwards counting until the word "recall." At the word "recall" $\mathrm{S}$ was to repeat the most recently presented consonant trigram.

\section{Results}

Simply stated (see Table 1), the manipulation of emotion, or at least this particular emotion, had little or no effect on the ultimate performance $\left(x^{2}, 1.870 ; \mathrm{df}, 3\right)$, while the standard task had the expected effect of depression of performance $\left(x^{2}, 6.50 ; \mathrm{df}, 1 ; \mathrm{P}<.02\right)$ :

\section{Experiment 2}

In this experiment, the intent was to increase the control by the actual prohibition, through posthypnotic suggestion, of rehearsal in the interpolated time interval.

\section{Method}

$\mathrm{S}$ was the same as in Experiment 1. It was specified, however, in addition to the constraints of Experiment 1, some blocks of trials would be designated either "nonpermissible", or "permissible tap." In the "non-permissible" trials, $\mathrm{S}$ was not to think of the trigram until the word "recall"; for the "permissible tap" trials, S was instructed that, when $\mathrm{E}$ tapped a pencil on the apparatus, $\mathrm{S}$ would be permitted one and only one rehearsal of the trigram at that time; for the rest of the interval, he was to behave as though he were in a "nonpermissible" block of trials.

\section{Results}

The most obvious effect present in these three conditions-non-permissible, permissible tap immediate, and permissible tap late (after $1 / 2$ the specified interval had elapsed)-is that the simple control of rehearsal

Table 1. Correct Responses per condition

\begin{tabular}{|c|c|c|c|c|c|c|}
\hline & \multirow[b]{2}{*}{ Seconds } & \multicolumn{3}{|c|}{$\begin{array}{l}\text { Levels of } \\
\text { Pleasure }\end{array}$} & \multirow{2}{*}{\multicolumn{2}{|c|}{$\begin{array}{cc}\begin{array}{r}\text { Counting } \\
\text { Backwards }\end{array} \\
3 & 4\end{array}$}} \\
\hline & & 0 & 1 & 2 & & \\
\hline Permissible Trials: 3 Blocks & 4 & 6 & 6 & 6 & 5 & 2 \\
\hline of 20 Trials & 16 & 6 & 6 & 6 & 6 & 1 \\
\hline Non-permissible Trials: 3 & 4 & 1 & 0 & 2 & 1 & 0 \\
\hline Blocks of 20 Trials & 16 & 0 & 1 & 1 & 0 & 0 \\
\hline Permissible Tap: Immediate: & 4 & 4 & 1 & 3 & 3 & 2 \\
\hline 2 Blocks of Trials & 16 & 2 & 1 & 3 & 1 & 1 \\
\hline Permissible Tap: Delayed: & 4 & 4 & 4 & 4 & 3 & 2 \\
\hline 2 Blocks of 20 Trials & 16 & 1 & 0 & 0 & 0 & 3 \\
\hline
\end{tabular}


yields results comparable with those obtained by the standard method of control of interpolated activity, without the danger of specific interference of items (see Table 1). $x^{2}$ for permissible vs. non-permissible trials was 60.05 ; df, $1 ; \mathrm{P}<.001$. Further, the control allowing single rehearsal of items indicates a promising interaction between early and late rehearsal and time of memory, perhaps indicating an optimal time for rehearsal of an item. Although $4 \mathrm{sec}$. vs. $16 \mathrm{sec}$. was a highly significant $\left(x^{2}, 14.486\right.$; df, $\left.1 ; \mathrm{P}<.0001\right)$ relationship in the usual direction, and there was absolutely no difference in totals for immediate vs. delayed conditions, an ordering of facilitation on the basis of length of inerval from stimulus to rehearsal yields 8,0 , and $2 \mathrm{sec}$, in ascending order of facilitation $\left(x^{2}, 8.04\right.$; df, 2; $\mathrm{P}<.02)$. This, coupled with the lack of significance for other interactions points to the importance of the stimulus-rehearsal interval, an interval susceptible only to as specific control as represented here.

\section{Summary and Conelusions}

Hypnotic control may be used as a means of specifying the exact nature of the interpolated interval in shortterm memory, allowing for investigation of such items as time of rehearsal, amount of rehearsal and the like in a direct fashion. Conclusions for this demonstrative paper are limited to (a) a strong indication that level of non-specific emotion is unrelated to memorial capacities and (b) while presence or absence or rehearsal is the dominant factor in determining performance in memory tasks, such variables as stimulus-rehearsal interval bear exploration.

\section{References}

UNDERWOOD, B. J., \& SCHULZ, R. W. Meaningfulness and verbal learning. Philadelphia: J. B. Lippincott Co., 1960.

PETERSON, L., \& PETERSON, MARGARET J. Shortterm retention of individual items. J. exp. Psychol., $1959,58,193-198$.

\section{Notes}

1. This research was conducted during the author's tenure as a USPHS Predoctoral Research Fellow at the University of Michigan.

2. The author wishes to thank Dr. G. S. Blum, who served as hypnotist, and R. Crowder, who aided in the design of Experiment 1. 